\title{
Effects of Cervical Kyphosis on Recovery From Dysphagia After Stroke
}

\author{
Suk Kyoung Kim, $\mathrm{MD}^{1}$, Sang Jun $\mathrm{Mo}, \mathrm{MD}^{1}$, Won Sik Moon, $\mathrm{MD}^{1}$, Po Song Jun, $\mathrm{MD}^{1}$, Chung Reen Kim, $\mathrm{MD}^{2}$ \\ ${ }^{1}$ Department of Rehabilitation Medicine, Dong-Eui Medical Center, Busan; ${ }^{2}$ Department of Physical Medicine and \\ Rehabilitation, Ulsan University Hospital, University of Ulsan College of Medicine, Ulsan, Korea
}

\begin{abstract}
Objective To determine the effects of cervical kyphosis on the recovery of swallowing function in subacute stroke patients.

Methods Baseline and 1-month follow-up videofluoroscopic swallowing studies (VFSSs) of 51 stroke patients were retrospectively analyzed. The patients were divided into the cervical kyphosis (Cobb's angle $<20^{\circ}, \mathrm{n}=27$ ) and control ( $\mathrm{n}=24$ ) groups. The penetration-aspiration scale (PAS), American Speech-Language-Hearing Association National Outcomes Measurement System swallowing scale (ASHA NOMS), and videofluoroscopic dysphagia scale (VDS) were used to determine the severity of dysphagia. Finally, the prevalence of abnormal VFSS findings was compared between the two groups.

Results There were no significant differences in baseline PAS, ASHA NOMS, and VDS scores between the two groups. However, the follow-up VDS scores in the cervical kyphosis group were significantly higher than those in the control group $(\mathrm{p}=0.04)$, and a follow-up study showed a tendency towards worse ASHA NOMS scores $(\mathrm{p}=0.07)$ in the cervical kyphosis group. In addition, the cervical kyphosis group had a higher occurrence of pharyngeal wall coating in both baseline and follow-up studies, as well as increased aspiration in follow-up studies $(\mathrm{p}<0.05)$. Conclusion This study showed that stroke patients who had cervical kyphosis at the time of stroke might have impaired recovery from dysphagia after stroke.
\end{abstract}

Keywords Kyphosis, Degulgitation disorders, Stroke, Respiratory aspiration, Fluoroscopy

\section{INTRODUCTION}

When viewed from the side, a healthy cervical spine shows C-shaped lordosis owing to the taller anterior compared with the posterior aspect of the vertebrae. The normal angle of curvature varies according to sex, age, and measuring methods of reporters. Various methods are currently used to measure the curvature of the cervical spine, including McGregor's line and the Harrison posterior tangent method; however, measurement of

Received December 15, 2015; Accepted April 26, 2016

Corresponding author: Chung Reen Kim

Department of Physical Medicine and Rehabilitation, Ulsan University Hospital, 877, Bangeojinsunhwando-ro, Dong-gu, Ulsan 44033, Korea. Tel: +8252-250-8730, Fax: +82-52-250-7211, E-mail: tikira@naver.com

ORCID: Suk Kyoung Kim (http://orcid.org/0000-0002-8656-3933); Sang Jun Mo (http://orcid.org/0000-0003-1861-4636); Won Sik Moon (http://orcid. org/0000-0001-9890-5913); Po Song Jun (http://orcid.org/0000-0001-7288-2135); Chung Reen Kim (http://orcid.org/0000-0002-0528-6189).

(c) This is an open-access article distributed under the terms of the Creative Commons Attribution Non-Commercial License (http://creativecommons.org/ licenses/by-nc/4.0) which permits unrestricted noncommercial use, distribution, and reproduction in any medium, provided the original work is properly cited. Copyright (C) 2016 by Korean Academy of Rehabilitation Medicine 
Cobb's angle is the most commonly used method, which defines angles between $20^{\circ}$ and $60^{\circ}$ as normal cervical curvature [1].

Nevertheless, the cervical curvature gradually changes with age and this altered posture of the cervical spine can progress to cervical kyphosis, also referred to as straight neck or forward head posture. This is a common musculoskeletal disorder in the elderly population [2]. Cervical kyphosis can occur as a result of iatrogenic processes or systemic arthritides such as degenerative disc disease, external trauma, neoplastic disease, infection, ankylosing spondylitis, or rheumatoid arthritis; it can also occur without underlying diseases [3]. Cervical kyphosis can cause pain in the cervical spine, neuropathic pain, and neurologic problems such as muscle weakness, sensory impairment, or gait impairment due to pressure on the spinal cord or spinal nerve roots; in severe cases, it may cause tetraplegia or respiratory difficulties $[1,3,4]$. Moreover, several studies have reported an association with dysphagia [2,3]. There are reports of cervical kyphosis causing an acute bend in the mid-esophagus, leading to swallowing difficulty [5].

When cervical kyphosis is accompanied by dysphagia, it may aggravate disorders of the pharynx [1]. These disorders also show a high incidence in stroke patients, separate from that of cervical kyphosis. Stroke patients show motor impairments of the pharynx due to delayed pharyngeal transit time, reduced pharyngeal contraction, and impaired coordination, and these symptoms are common irrespective of the affected brain region [6]. In particular, $21 \%-42 \%$ of stroke patients develop aspiration problems as a result of disorders of the pharynx [7], which ultimately increases the incidence of nutritional deficiency, dehydration, and aspiration pneumonia, which are important factors that may reduce the quality of life in stroke patients.

However, if cervical kyphosis can affect the recovery from dysphagia in stroke patients, understanding the correlations between these two conditions could be important for developing rehabilitation therapy for dysphagia. Therefore, we used a videofluoroscopic swallowing study (VFSS) in subacute stroke patients with dysphagia to investigate the effects of cervical kyphosis on swallowing disorders and their recovery.

\section{MATERIALS AND METHODS}

\section{Subjects}

Subacute stroke patients who had experienced stroke within 3 months were selected to participate in this study, from among stroke patients with dysphagia who were at least 60 years of age and who were hospitalized at the study hospital between December 2012 and May 2015. Only patients with first stroke, confirmed by verifying the presence of cerebral infarction or hemorrhage with brain magnetic resonance imaging or computed tomography, were selected. Patients were excluded if they had previously undergone neck or cervical spine surgery, if they showed suspicious mechanical obstruction by osteophytes on the anterior aspect of the cervical spine or diffuse idiopathic skeletal hyperostosis, if a Zenker diverticulum was discovered on VFSS, if dysphagia rehabilitation therapy was discontinued because of complications such as pneumonia, or if they were intubated with an endotracheal tube. This study was approved by the Institutional Review Board of Dong-Eui Hospital.

\section{Methods}

This was a retrospective case-control study. Medical records and VFSS data were collected for all subjects enrolled in the study. The patients were divided into the cervical kyphosis and control groups on the basis of lateral cervical spine radiographic images, and the extent of dysphagia was compared between the two groups. Baseline VFSSs were performed in the subacute stage after stroke, and again at follow-up 4 weeks later. The baseline and follow-up results were compared between the two groups; the magnitude of changes between baseline and follow-up results within groups was also compared. After baseline assessment, all subjects received dysphagia rehabilitation therapy and education, according to the degree of swallowing disorder, three times a week.

Cobb's angles were measured to assess patients for cervical kyphosis. Before performing the VFSS, the patients sat comfortably with their gaze turned $15^{\circ}$ upward, while a lateral radiograph of the cervical spine was obtained. By using this image, Cobb's angle was calculated between C2 and C7. This angle was obtained by drawing a line parallel to the lower endplate of $\mathrm{C} 2$ and another line parallel to the lower endplate of $\mathrm{C} 7$, drawing two lines orthogonal to each of these lines, and measuring the intersection angle 
of the two orthogonal lines [8] (Fig. 1). Angles $<20^{\circ}$ were classified as cervical kyphosis. Cobb's angle is known to be reliable, with a significant intraclass correlation coefficient of at least 0.7 [9].

The VFSS was performed by using a modification of Logemann's protocol [10]. With each patient positioned sideways to the camera, fluoroscopic imaging was performed as the patient swallowed water, followed by pudding, and then rice. Barium was diluted in water, and the other food items were also mixed with barium so that they could be observed with fluoroscopy. The VFSS was adapted according to the physical condition, compliance, and dysphagia severity of each patient.

The penetration-aspiration scale (PAS), American Speech-Language-Hearing Association National Outcomes Measurement System swallowing scale (ASHA NOMS), and videofluoroscopic dysphagia scale (VDS) scores were also obtained on the basis of medical records and VFSS results, to compare the dysphagia severity between the two groups. The qualitative and quantitative results for the 14 specific items of the VDS were also compared between the two groups.

The PAS was developed to observe penetration and aspiration, and to objectively verify the presence of aspiration [11]. In this scale, 1 point indicates that food does not enter the airway, 2-5 points indicate penetration,

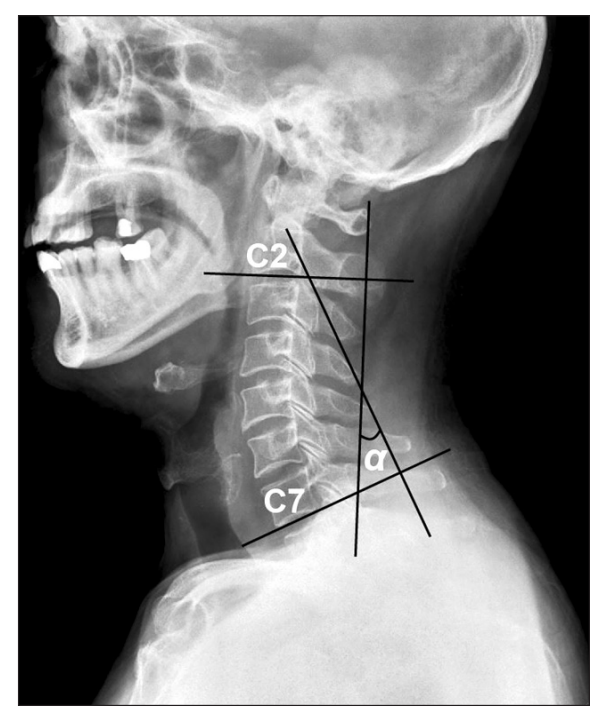

Fig. 1. Cobb's method for measuring cervical lordosis. Cervical lordotic angles $(\alpha)$ are measured by joining perpendiculars to lines drawn parallel to the lower end plates of $\mathrm{C} 2$ and $\mathrm{C} 7$. and 6-8 points indicate aspiration. Cases that show silent aspiration are assigned a score of 8 points, and higher scores represent a higher risk of aspiration. The ASHA NOMS evaluates the extent of dietary function and restrictions in patients. The scale is graded from level 1 , in which the patient cannot eat anything orally and obtains all nutrients through non-oral means, to level 7, in which the patient can swallow all types of nutritional foods orally, without restrictions. Lower levels signify more severe dysphagia [12]. The VDS grades the swallowing difficulty on the basis of the assessment of 14 signs observed in dysphagic patients during VFSSs. Higher scores indicate more severe dysphagia [13]. The 14 signs used in the VDS are divided into two phases; the oral phase consisting of lip closure, bolus formation, mastication, apraxia, tongue to palate contact, premature bolus loss, and oral transit time, and the pharyngeal phase consisting of reduced laryngeal elevation and epiglottic closure, vallecular residue, pyriform sinus residue, coating of the pharyngeal wall after swallowing, pharyngeal delay time, pharyngeal transit time, and aspiration. Each sign was included in the analysis and compared between the two groups.

All statistical analyses were performed by using IBM SPSS Statistics for Windows ver. 21.0 (IBM Corp., Armonk, NY, USA) and R package ver. 3.0.2 (R Foundation for Statistical Computing, Vienna, Austria). Fisher exact tests were used to investigate differences in the general characteristics of the two groups, and Mann-Whitney U tests were used to compare the PAS, ASHA NOMS, and VDS scores between the two groups during the baseline and follow-up studies, as well as to compare the two groups in terms of the differences in the baseline and follow-up scores. In addition, Fisher exact test was used to investigate the correlations between the two groups for the 14 variables in the VDS. The significance level was set at 0.05 .

\section{RESULTS}

\section{Patient characteristics and demographics}

A total of 51 patients were included in the study (28 men and 23 women). There were 37 patients and 14 patients with cerebral infarction and cerebral hemorrhage, respectively. The measurement of Cobb's angle in lateral cervical radiographs showed that there were 27 patients (53\%) with cervical kyphosis and 24 patients (47\%) with 
normal curvature of the cervical spine. The cervical kyphosis group had a mean Cobb's angle of $8.78^{\circ} \pm 4.35^{\circ}$, and the control group had a mean Cobb's angle of $30.73^{\circ} \pm 4.88^{\circ}$. Among the patients in the cervical kyphosis group, 8 had an angle between $10^{\circ}$ and $20^{\circ}, 19$ had an angle of $\leq 10^{\circ}$, and none of the patients had an angle of $\leq 0^{\circ}$ which indicated severe cervical kyphosis. There was no significant difference between the two groups in terms of the time from stroke to VFSS, age, and lesion location, or in the other general characteristics (Table 1).

Differences in the dysphasia scale scores between the cervical kyphosis and control groups

The results of the three dysphagia scale scores for the two groups are presented in Table 2. In the cervical kyphosis and control groups, the mean baseline PAS scores at the first VFSS were $7.10 \pm 1.29$ and $6.75 \pm 1.59$, respectively, whereas the PAS scores at the follow-up examination were $5.67 \pm 2.23$ and $4.13 \pm 2.50$ respectively, showing no significant differences between the two groups. Both groups showed improvement in the follow-up examination after 1 month; however, there was no statistically significant difference between the two groups in terms of the change from the baseline study to the follow-up study.

In the cervical kyphosis and control groups, the mean baseline ASHA NOMS scores were $2.70 \pm 1.44$ and $2.83 \pm 1.46$, respectively, whereas the scores in the followup examination were $3.96 \pm 1.56$ and $4.67 \pm 1.55$, respectively. Although the difference was not significant, the control group tended to show a larger improvement $(p=0.07)$. The change in the ASHA NOMS score between the baseline study and follow-up study did not show a statistically significant difference between the two groups.

The mean baseline VDS scores were $46.85 \pm 14.46$ in the cervical kyphosis group and $40.63 \pm 12.52$ in the control group, but there was no statistically significant difference. However, in the follow-up examinations, the VDS scores were $33.7 \pm 14.24$ and $25.92 \pm 14.66$, respectively, showing a statistically significant improvement in the control group $(p=0.04)$. Nevertheless, the change in scores between the first and the follow-up studies did not show a statistically significant difference between the two groups.

VDS differences between the cervical kyphosis and control groups

The comparison of the presence or absence of the 14

Table 1. Demographic and clinical characteristics

\begin{tabular}{|c|c|c|c|}
\hline Characteristic & Control group $(n=24)$ & Cervical kyphosis group $(n=27)$ & p-value \\
\hline Cobb's angle $\left({ }^{\circ}\right)$ & $30.73 \pm 4.88$ & $8.78 \pm 4.35$ & \\
\hline$\geq 20^{\circ}$ and $\leq 40^{\circ}$ & 24 & 0 & \\
\hline$<20^{\circ}$ & 0 & 8 & \\
\hline$<10^{\circ}$ & 0 & 19 & \\
\hline$<0^{\circ}$ & 0 & 0 & \\
\hline Age (yr) & $71.75 \pm 7.12$ & $74 \pm 6.85$ & 0.54 \\
\hline$<70$ & 9 & 7 & \\
\hline $70-79$ & 13 & 15 & \\
\hline$\geq 80$ & 2 & 5 & \\
\hline Sex (male:female) & 13:11 & $15: 12$ & 0.57 \\
\hline Stroke type (ischemic:hemorrhagic) & $18: 6$ & 19:8 & 0.48 \\
\hline Stroke laterality (right:left:bilateral) & $9: 11: 4$ & 11:15:1 & 0.33 \\
\hline Stroke location & & & 0.44 \\
\hline Cortex & 7 & 4 & \\
\hline Subcortex & 14 & 20 & \\
\hline Brainstem & 3 & 3 & \\
\hline Days from stroke to first study & $50.08 \pm 38.3$ & $48.3 \pm 23.6$ & 0.53 \\
\hline
\end{tabular}

Values are presented as mean \pm standard deviation or number.

Statistically significant as $\mathrm{p}<0.05$. 


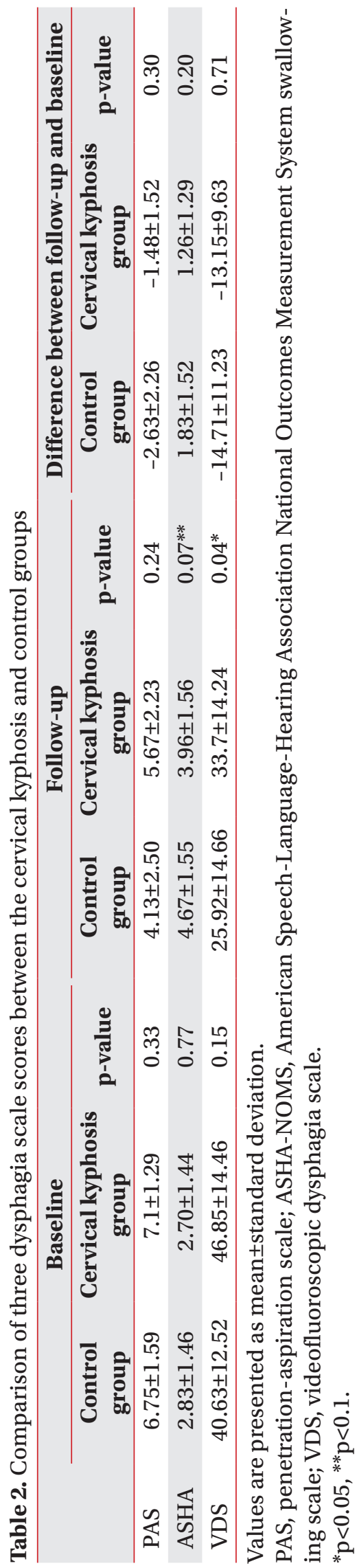

VDS items in the baseline examination showed that the cervical kyphosis group had a significantly higher incidence of problems related to mastication and coating of the pharyngeal wall after swallowing than the control group (Table 3 ). There were no statistically significant differences in any of the other signs. In the follow-up examination, although both groups showed improvements in coating of the pharyngeal wall after swallowing, there was still a significantly higher frequency of coating problems in the cervical kyphosis group than in the control group. In addition, although aspiration did not differ significantly between the two groups in baseline examinations, its frequency was significantly higher in the cervical kyphosis group during follow-up examinations, suggesting that aspiration did not resolve well in patients with cervical kyphosis.

\section{DISCUSSION}

In the present study, we investigated stroke patients with cervical kyphosis to determine the effect of kyphosis on swallowing function. Cervical kyphosis was identified in $53 \%$ of the study participants. Although the patients with cervical kyphosis did not show large differences from the control group soon after stroke, the rate of recovery from dysphagia was worse than that in the control group after 4 weeks. In particular, the risk of aspiration persisted in the cervical kyphosis group, indicating that care must be taken to avoid aspiration during the early stages after stroke in patients with cervical kyphosis.

Modern lifestyle patterns and aging have led to a gradual increase in the rate of degenerative changes to the cervical spine. Degenerative cervical spine disease occurs during the lifetime in more than two-thirds of the overall population [14]. Although the precise prevalence of degenerative cervical kyphosis has not been reported, one study reported that the prevalence of cervical kyphosis was $66 \%$ in a population of typical 30 - to 50 -year-old adults [15]. Although the subjects in this study were restricted to stroke patients with dysphagia, a comorbidity rate of $53 \%$ was observed, demonstrating the high prevalence of cervical kyphosis.

Cervical kyphosis can cause various neurologic problems, and in severe cases, it may be accompanied by quadriplegia or sensory impairments as a result of spinal cord or nerve root compression. It can also cause dif- 
Table 3. Comparison of the 14 signs used in the videofluoroscopic dysphasia scale between the cervical kyphosis and control groups

\begin{tabular}{|c|c|c|c|c|c|c|}
\hline & & Baseline & & & Follow-up & \\
\hline & $\begin{array}{l}\text { Control } \\
\text { group }\end{array}$ & $\begin{array}{l}\text { Cervical } \\
\text { kyphosis } \\
\text { group }\end{array}$ & p-value & $\begin{array}{l}\text { Control } \\
\text { group }\end{array}$ & $\begin{array}{l}\text { Cervical } \\
\text { kyphosis } \\
\text { group }\end{array}$ & p-value \\
\hline Lip closure & & & 1.00 & & & 1.00 \\
\hline Intact & $23(46.94)$ & $26(53.06)$ & & $24(48)$ & $26(52)$ & \\
\hline Inadequate & $1(50)$ & $1(50)$ & & $0(0)$ & $1(100)$ & \\
\hline Bolus formation & & & 0.13 & & & 0.16 \\
\hline Intact & $6(75)$ & $2(25)$ & & $7(70)$ & $3(30)$ & \\
\hline Inadequate & $18(41.86)$ & $25(58.14)$ & & $17(41.46)$ & $24(58.54)$ & \\
\hline Mastication & & & $0.04^{*}$ & & & 0.25 \\
\hline Intact & $14(53.85)$ & $12(46.15)$ & & $14(41.18)$ & $20(58.82)$ & \\
\hline Inadequate & $7(31.82)$ & $15(68.18)$ & & $10(58.82)$ & $7(41.18)$ & \\
\hline None & $3(100)$ & $0(0)$ & & 0 & 0 & \\
\hline Apraxia & & & 0.86 & & & 0.42 \\
\hline None & $12(42.86)$ & $16(57.14)$ & & $15(40.54)$ & $22(59.46)$ & \\
\hline Mild & $6(54.55)$ & $5(45.45)$ & & $7(63.64)$ & $4(36.36)$ & \\
\hline Moderate & $5(45.45)$ & $6(54.55)$ & & $2(66.67)$ & $1(33.33)$ & \\
\hline Severe & $1(100)$ & $0(0)$ & & $0(0)$ & $0(0)$ & \\
\hline Tongue to palate contact & & & 0.28 & & & 1.00 \\
\hline Intact & $6(66.67)$ & $3(33.33)$ & & $10(47.62)$ & $11(52.38)$ & \\
\hline Inadequate & $18(42.86)$ & $24(57.14)$ & & $14(46.67)$ & $16(53.33)$ & \\
\hline Premature bolus loss (\%) & & & 0.97 & & & 0.68 \\
\hline None & $9(47.37)$ & $10(52.63)$ & & $8(40)$ & $12(60)$ & \\
\hline$<10$ & $3(50)$ & $3(50)$ & & $11(55)$ & $9(45)$ & \\
\hline $10-50$ & $8(42.11)$ & $11(57.89)$ & & $5(50)$ & $5(50)$ & \\
\hline$>50$ & $4(57.14)$ & $3(42.86)$ & & $0(0)$ & $1(100)$ & \\
\hline Oral transit time (s) & & & 0.78 & & & 0.36 \\
\hline$\leq 1.0$ & $12(50)$ & $12(50)$ & & $15(41.67)$ & $21(58.33)$ & \\
\hline$>1.0$ & $12(44.44)$ & $15(55.56)$ & & $9(60)$ & $6(40)$ & \\
\hline Residue on the valleculae (\%) & & & 0.64 & & & 0.29 \\
\hline None & $3(60)$ & $2(40)$ & & $7(70)$ & $3(30)$ & \\
\hline$<10$ & $8(57.14)$ & $6(42.86)$ & & $10(47.62)$ & $11(52.38)$ & \\
\hline $10-50$ & $9(37.5)$ & $15(62.5)$ & & $6(33.33)$ & $12(66.67)$ & \\
\hline$>50$ & $4(50)$ & $4(50)$ & & $1(50)$ & $1(50)$ & \\
\hline $\begin{array}{l}\text { Reduced laryngeal elevation } \\
\text { and epiglottic closure }\end{array}$ & & & 1.00 & & & 0.27 \\
\hline No & $8(47.06)$ & $9(52.94)$ & & $14(56)$ & $11(44)$ & \\
\hline Yes & $16(47.06)$ & $18(52.94)$ & & $10(38.46)$ & $16(61.54)$ & \\
\hline Residue in the pyriform sinuses (\%) & & & 1.00 & & & 1.00 \\
\hline None & $13(48.15)$ & $14(51.85)$ & & $19(48.72)$ & $20(51.28)$ & \\
\hline$<10$ & $6(42.86)$ & $8(57.14)$ & & $3(42.86)$ & $4(57.14)$ & \\
\hline $10-50$ & $3(50)$ & $3(50)$ & & $2(40)$ & $3(60)$ & \\
\hline$>50$ & $2(50)$ & $2(50)$ & & $0(0)$ & $0(0)$ & \\
\hline
\end{tabular}


Table 3. Continued

\begin{tabular}{|c|c|c|c|c|c|c|}
\hline & \multicolumn{3}{|c|}{ Baseline } & \multicolumn{3}{|c|}{ Follow-up } \\
\hline & $\begin{array}{c}\text { Control } \\
\text { group }\end{array}$ & $\begin{array}{l}\text { Cervical } \\
\text { kyphosis } \\
\text { group }\end{array}$ & p-value & $\begin{array}{l}\text { Control } \\
\text { group }\end{array}$ & $\begin{array}{c}\text { Cervical } \\
\text { kyphosis } \\
\text { group }\end{array}$ & p-value \\
\hline $\begin{array}{l}\text { Coating of the pharyngeal wall } \\
\text { after swallowing }\end{array}$ & & & $0.01^{*}$ & & & $0.02^{*}$ \\
\hline No & $15(68.18)$ & $7(31.82)$ & & $21(58.33)$ & $15(41.67)$ & \\
\hline Yes & $9(31.03)$ & $20(68.97)$ & & $3(20)$ & $12(80)$ & \\
\hline Pharyngeal delay time (s) & & & 0.57 & & & 0.53 \\
\hline$\leq 0.5$ & $16(51.61)$ & 15 (48.39) & & $16(43.24)$ & $21(56.76)$ & \\
\hline$>0.5$ & $8(40)$ & $12(60)$ & & $8(57.14)$ & $6(42.86)$ & \\
\hline Pharyngeal transit time (s) & & & 0.61 & & & 1.00 \\
\hline$\leq 1.0$ & $23(48.94)$ & $24(51.06)$ & & $24(48)$ & $26(52)$ & \\
\hline$>1.0$ & $1(25)$ & $3(75)$ & & $0(0)$ & $1(100)$ & \\
\hline Aspiration & & & 0.79 & & & $0.00^{*}$ \\
\hline None & $1(100)$ & $0(0)$ & & $7(58.33)$ & $5(41.67)$ & \\
\hline Supraglottic penetration & $2(50)$ & $2(50)$ & & $7(100)$ & $0(0)$ & \\
\hline Subglottic aspiration & $21(45.65)$ & $25(54.35)$ & & $10(31.25)$ & $22(68.75)$ & \\
\hline
\end{tabular}

Values are presented as number (\%).

${ }^{*} \mathrm{p}<0.05$.

ficulties with the anterior gaze, dysphagia, and difficulty in breathing [4]. A study performed in 2003 investigated 78 patients who underwent surgery after a diagnosis of symptomatic cervical spine instability or cervical kyphosis, and it reported that 10 patients had dysphagia before surgery as a result of severe cervical kyphosis [16]. Although none of the participants in the present study had severe cervical kyphosis, the results confirmed that even non-severe cervical kyphosis in subacute stroke patients could negatively affect the recovery of the swallowing function.

The primary cause of cervical kyphosis-related pharyngeal disorders is thought to be weakening of the deep cervical flexors (DCFs). In other words, cervical kyphosis may have caused weakening of the deep cervical neck muscles before the stroke. Even if the kyphosis was not severe enough to cause dysphagia before the stroke, weakness of the pharyngeal muscles may have led to more severe impairment of swallowing function after stroke, and ultimately impaired the recovery of patients.

DCFs are a group of muscles on the front side of the cervical spine that act to stabilize the head-on-neck posture. DCFs consist of the following muscles: rectus capitis anterior, rectus capitis lateralis, longus capitis, and lon- gus colli. Although the DCFs are adjacent to the pharynx, none of the studies have reported a clear association between the DCFs and dysphagia. However, the DCFs play an important role in maintaining the curvature of the cervical spine and regulating intervertebral movement. It is well-known that the DCFs are weakened in cervical kyphosis $[17,18]$. Although the DCFs do not play a major role in swallowing function, a review article on dysphagia related to cervical and postural disorders suggested that weakening of the DCFs (longus colli and longus capitis) could cause problems in the swallowing process [1]. In particular, the longus colli muscle stabilizes the cervical spine during talking, coughing, and swallowing, and weakening of this muscle reduces stability during swallowing [19].

The role of the DCFs can also be considered in relation to the effectiveness of the Shaker exercise in patients with pharyngeal dysphagia. The Shaker exercise prevents aspiration during swallowing by strengthening the suprahyoid and infrahyoid muscles, thus increasing the anterior excursion of the pharynx to maximize the anteroposterior diameter and also increasing the cross-sectional area of the upper esophageal sphincter opening [20,21]. Although the purpose of the Shaker exercise is to strength- 
en the submental muscles including the suprahyoid and infrahyoid muscles, previous studies reported that DCFs including longus colli, longus capitis and rectus capitis were also activated during the Shaker exercise [22,23]. In fact, the posture during the Shaker exercise is similar to that during the exercises that strengthen the DCFs. In a supine position, after flexing the head and neck towards the chest (chin to chest), the patient performs isometric holding; thus, strengthening the longus colli and longus capitis in a manner similar to combined craniocervical flexion with cervical flexion or the Shaker exercise [24]. On the contrary, the DCF exercises strengthen the submental muscles as well as deep neck flexors like the Shaker exercise. The short neck flexion exercise has been reported to effectively strengthen the suprahyoid, infrahyoid, longus capitis, and rectus capitis lateralis muscles [25]. However, the evidence about the effects of DCF on swallowing function is not sufficient; hence, further investigations are necessary to evaluate the direct effects of DCF exercise on recovery from swallowing dysfunction in stroke patients.

It is also possible that cervical kyphosis causes weakening of the pharyngeal muscles themselves. In the current study, the presence of pharyngeal wall coating was observed significantly more frequently in the cervical kyphosis group during both baseline and follow-up examinations. This finding indicates weakness of pharyngeal muscles in stroke patients with cervical kyphosis. Pharyngeal wall coating is related to pharyngeal stasis, which is the main cause of aspiration. Although there was no difference between the two groups in terms of residue, the frequency of pharyngeal wall coating was increased in the cervical kyphosis group due to weakening of the pharyngeal muscles. If this causes food to remain on the posterior surface of the hypopharynx or the epiglottis, the food can enter the trachea during breathing as a result of gravity or the milking action of the arytenoids [4]. This may be related to the continued presence of aspiration at follow-up in a large number of patients in the cervical kyphosis group in the current study. However, none of the studies have reported that cervical kyphosis causes weakening of the pharyngeal muscles; thus, it is difficult to elucidate the exact mechanism. The contraction of the pharyngeal muscles is likely to be affected by the neck position; if this continues over a long period, it may cause gradual weakening of the pharyngeal muscles.
In the future, this relationship should be evaluated more clearly through electrodiagnostic studies of the pharyngeal muscles in patients with cervical kyphosis.

Meanwhile, the current study demonstrated that aspiration persists in stroke patients with cervical kyphosis; this is a highly important discovery, as aspiration increases the risk of pneumonia. Therefore, it is essential to treat kyphosis in addition to performing swallowing rehabilitation therapy in patients with cervical kyphosis. In addition, indirectly strengthening the suprahyoid and infrahyoid muscles as well as the longus capitis, longus colli, and the other DCFs through exercises such as the Shaker exercise may more effectively treat delayed recovery from dysphagia due to cervical kyphosis. The DCF strengthening exercises described above could further improve recovery from dysphagia. Although the Shaker exercises are already known to be effective in stroke patients, their effectiveness might be further increased by dividing stroke patients into groups based on cervical kyphosis in order to investigate the effects of muscle strengthening exercises on kyphosis. In addition, the usefulness of current treatment methods for cervical spine alignment, including the cervical extension-traction method and the Denneroll cervical orthotic device $[26,27]$, should also be investigated in dysphagia.

The current study has several limitations. First, the number of subjects was not large, and none of the patients had severe cervical kyphosis. This limited the ability of the current study to clearly ascertain the relationship between cervical kyphosis and dysphagia. Additional studies among patients with a more varied range of cervical kyphosis are necessary. In addition, because only stroke patients with dysphagia were recruited into this study, it was difficult to determine the prevalence of cervical kyphosis among all stroke patients. Furthermore, it was difficult to make detailed comparisons according to the severity or the chronicity of stroke; additional studies with more patients may be helpful in better understanding the relationship between cervical kyphosis and dysphagia in stroke patients. Finally, it was not possible to investigate the effects of kyphosis treatment together with swallowing rehabilitation treatment in the patient group with cervical kyphosis; future studies are necessary to compare the effects of this treatment plan.

In conclusion, a considerable number of stroke patients had cervical kyphosis at the time of stroke; in these pa- 
tients, the recovery of swallowing function, especially pharyngeal function, was impaired compared with that in patients without kyphosis. Therefore, the results of this study demonstrate the need for early, detailed observations of the degree of cervical kyphosis in patients who experience swallowing difficulties due to stroke. Additional research is necessary to determine how strengthening the DCFs and other neck muscles helps in recovery from swallowing difficulties in patients with dysphagia accompanied by cervical kyphosis. This information could be significantly beneficial for developing swallowing rehabilitation therapy.

\section{CONFLICT OF INTEREST}

No potential conflict of interest relevant to this article was reported.

\section{REFERENCES}

1. Papadopoulou S, Exarchakos G, Beris A, Ploumis A. Dysphagia associated with cervical spine and postural disorders. Dysphagia 2013;28:469-80.

2. Kauffman T. Posture and age. Top Geriatr Rehabil 1987;2:13-28.

3. Han K, Lu C, Li J, Xiong GZ, Wang B, Lv GH, et al. Surgical treatment of cervical kyphosis. Eur Spine J 2011;20:523-36.

4. Rhee JM. Iatrogenic cervical deformity. Semin Spine Surg 2011;23:173-80.

5. Goyal N, Narlawar R, Garrett A. Kyphosis, a rare cause of dysphagia. Age Ageing 2005;34:521-2.

6. Crary MA. Adult neurologic disorders. In: Groher ME, Crary MA, editors. Dysphagia: clinical management in adults and children. Maryland Heights: Mosby; 2009. p. 72-98.

7. Veis SL, Logemann JA. Swallowing disorders in persons with cerebrovascular accident. Arch Phys Med Rehabil 1985;66:372-5.

8. Freeman III BL. Scoliosis and kyphosis. In: Canale ST, Beatty JH, editors. Campbell's operative orthopaedics. 10th ed. St. Louis: Mosby; 2003. p. 1751-954.

9. Harrison DE, Harrison DD, Cailliet R, Troyanovich SJ, Janik TJ, Holland B. Cobb method or Harrison posterior tangent method: which to choose for lateral cervical radiographic analysis. Spine (Phila Pa 1976)
2000;25:2072-8.

10. Logemann JA. Evaluation and treatment of swallowing disorders. 2nd ed. Austin: Pro-Ed; 1998.

11. Rosenbek JC, Robbins JA, Roecker EB, Coyle JL, Wood JL. A penetration-aspiration scale. Dysphagia 1996;11:93-8.

12. American Speech-Language-Hearing Association. National Outcomes Measurement System (NOMS): adult speech-language pathology user's guide. Rockville: American Speech-Language-Hearing Association; 2003.

13. Jung SH, Lee KJ, Hong JB, Han TR. Validation of clinical dysphagia scale: based on videofluoroscopic swallowing study. J Korean Acad Rehabil Med 2005;29:34350.

14. Todd AG. Cervical spine: degenerative conditions. Curr Rev Musculoskelet Med 2011;4:168-74.

15. Griegel-Morris P, Larson K, Mueller-Klaus K, Oatis CA. Incidence of common postural abnormalities in the cervical, shoulder, and thoracic regions and their association with pain in two age groups of healthy subjects. Phys Ther 1992;72:425-31.

16. Matz PG, Wolff III CL, Hadley MN. Management of cervical kyphotic deformity. Semin Neurosurg 2003;14:55-60.

17. Janda V. Muscle and motor control in cervicogenic disorders. In: Grant R, editor. Physical therapy of the cervical and thoracic spine. 3rd ed. New York: Churchill Livingstone; 2002. p. 182-99.

18. Watson DH, Trott PH. Cervical headache: an investigation of natural head posture and upper cervical flexor muscle performance. Cephalalgia 1993;13:27284; discussion 232.

19. Johnson J. Postural correction. Champaign: Human Kinetics; 2015.

20. Logemann JA, Rademaker A, Pauloski BR, Kelly A, Stangl-McBreen C, Antinoja J, et al. A randomized study comparing the Shaker exercise with traditional therapy: a preliminary study. Dysphagia 2009;24:40311.

21. Mepani R, Antonik S, Massey B, Kern M, Logemann J, Pauloski B, et al. Augmentation of deglutitive thyrohyoid muscle shortening by the Shaker Exercise. Dysphagia 2009;24:26-31.

22. Mishra A, Rajappa A, Tipton E, Malandraki GA. The recline exercise: comparisons with the head lift exer- 
cise in healthy adults. Dysphagia 2015;30:730-7.

23. Falla DL, Jull GA, Hodges PW. Patients with neck pain demonstrate reduced electromyographic activity of the deep cervical flexor muscles during performance of the craniocervical flexion test. Spine (Phila Pa 1976) 2004;29:2108-14.

24. Cagnie B, Dickx N, Peeters I, Tuytens J, Achten E, Cambier D, et al. The use of functional MRI to evaluate cervical flexor activity during different cervical flexion exercises. J Appl Physiol (1985) 2008;104:230-5.

25. Don Kim K, Lee HJ, Lee MH, Ryu HJ. Effects of neck exercises on swallowing function of patients with stroke. J Phys Ther Sci 2015;27:1005-8.

26. Harrison DD, Jackson BL, Troyanovich S, Robertson G, de George D, Barker WF. The efficacy of cervical extension-compression traction combined with diversified manipulation and drop table adjustments in the rehabilitation of cervical lordosis: a pilot study. J Manipulative Physiol Ther 1994;17:454-64.

27. Ferrantelli J. BioPhysics insights: the Denneroll orthotic. Am J Clin Chiroprac 2010;20:13-4. 